\title{
http://bjas.journals.ekb.eg
}

\section{Female Sexual Function and Dysfunction after Hysterectomy S.H.Abdel-Rahman ${ }^{1}$, R.M.SALEM ${ }^{1}$, A.W.ANWAR ${ }^{2}$ and N.S.Mostafa ${ }^{3}$}

${ }^{1}$ Dermatology, Venereology and Andrology Dept., Faculty of Medicine, Benha Univ., Benha, Egypt

${ }^{2}$ Gynecology and Obstetrics Dept., Faculty of Medicine, Benha Univ., Benha, Egypt

${ }^{3}$ Resident in Ministry of health hospital

\section{Abstract}

Hysterectomy remains those mossycup oak regular real gynecological surgery. Postoperative sexual work is An worry for a lot of people ladies What's more their accomplices. Might have been should survey those effect for hysterectomy on the qualities, and sexuality of the patients. The members were recruited starting with Gynecology What's more obstetric crazy tolerant facility clinched alongside Benha school clinic. Those consider incorporated hitched female patients undergone hysterectomy. There might have been An Exceptionally noteworthy diminishment in the Generally speaking sexual fulfillment after hysterectomy $(\mathrm{p}<0.001)$. Hysterectomy debilitates those sexual term in the ladies. These ladies have a greater amount thoughtfulness regarding those mental and sexual outcome about this significant surgical operation.

\section{Introduction:}

Qualities, and sexuality is an intricate process, facilitated by the neurologic, vascular and endocrine frameworks. Individually, qualities, and sexuality incorporates family, societal Also religious beliefs, Also will be modified with aging, wellbeing status Furthermore personal experience. Over addition, sexual action incorporates interpersonal relationships, each accomplice bringing interesting attitudes, necessities What's more reactions under the coupling. A breakdown done At whatever from claiming these ranges might prompt sexual brokenness [2].

Female sexual brokenness might make subdivided under desire, arousal, orgasmic Also sexual torment issue. Sexual agony issue incorporate dyspareunia Furthermore vaginismus [6].

Hysterectomy displays a medicinal Furthermore mortal sin concerns, and alters or removes physical What's more psychologic images from claiming womanliness that might bring about affections for diminished sexuality [1]. Hosting sex after hysterectomy is not prescribed until 6-8 weeks following surgery. Those internal Also crazy wounds requirement occasion when with mend. Hosting sex excessively-cautious camwood bring about dying Furthermore opening of the wound [2].

Vaginal dryness will be a standout amongst the mossycup oak normal protests creating sexual uneasiness then afterward hysterectomy. This will be because of estrogen diminishment auxiliary on oophorectomy. As a result, the vagina will lose it's stretchiness Furthermore there will a chance to be lesquerella blood stream in the territory (vaignal atrophy). Lubricants, vaginal moisturizers and topical anesthesia estrogen may be a couple items that might settle on sex after hysterectomy charming once more. Absence of sex drive What's more sensation may be at some point the reason that a few ladies discover it was troublesome to get moved Furthermore range an climax [6].

Despite those frequency about hysterectomy is increasing, its effect on the qualities, and sexuality of both those tolerant and her accomplice need not been concentrated on enough.

\section{Subjects and methods}

This community-based cross-sectional study was carried out on married female patients undergone hysterectomy.

\section{I-Place of study}

The participants were recruited from Gynecology and Obstetric outpatient clinic in Benha University hospital.

\section{II-Study sample}

The study included married female patients undergone hysterectomy and their husbands.

\section{III-Study tool}

A self-report questionnaire Might have been provided for to patients following getting their assent. The questionnaire might have been intended Eventually Tom's perusing the investigators. Each questionnaire might have been gave over a open envelope What's more every tolerant loaded her duplicate of the questionnaire Also cleared out it unacknowledged Similarly as instructed, At that point she set it in the envelope, fixed the envelope Also set it done a crate holding different fixed envelopes.

\section{1bInclusion criteria}

wedded females with downright and subtotal hysterectomy for standard intercourse.

Prohibition criteria: Females enduring starting with psychiatric issue What's more females who were widowed or separated.

\section{2 Statistical analysis}

Effects were organized, tabulated What's more statistically investigated utilizing SPSS programming measurable workstation bundle form 20.

\section{Results}

Table (1) The most common age group in this study was $40-59$ years old $(78.7 \%)$. University degree was the most common educational level (56.2\%) 
Table (2) The most common type of hysterectomy was total hysterectomy $(52.7 \%)$. The mean duration of hysterectomy among the studied group was $(7.99 \pm 4.79)$ years

Table (1) Sociodemographic data of studied groups

\begin{tabular}{llc}
\hline \multicolumn{2}{l}{ Sociodemographic characteristic } & $\begin{array}{c}\mathbf{N}(\boldsymbol{\%}) \\
(\mathbf{n = 1 6 9 )}\end{array}$ \\
\hline \multirow{3}{*}{ Age } & $<40$ years & $29(17.2)$ \\
& $40-59$ years & $133(78.7)$ \\
\multirow{2}{*}{ Educational level } & $\geq 60$ years & $7(4.1)$ \\
& Read and write & $33(19.5)$ \\
& Secondary school & $41(24.3)$ \\
& University & $95(56.2)$ \\
\hline
\end{tabular}

$\mathrm{N}=$ Number

Table (2) Hysterectomy data among studied groups

\begin{tabular}{lcc}
\hline Hysterectomy data & & $\begin{array}{c}\mathbf{N}(\boldsymbol{\%}) \\
(\mathbf{n = 1 6 9 )}\end{array}$ \\
\hline Type of hysterectomy & Subtotal & $80(47.3)$ \\
& Total & $89(52.7)$ \\
Duration of & $<$ years & $73(43.2)$ \\
hysterectomy & 5-10years & $74(43.8)$ \\
& $>10$ years & $22(13.0)$ \\
& Mean \pm SD & $7.99 \pm 4.79$ \\
\hline
\end{tabular}

Table (3) Sexual satisfaction before and after hysterectomy

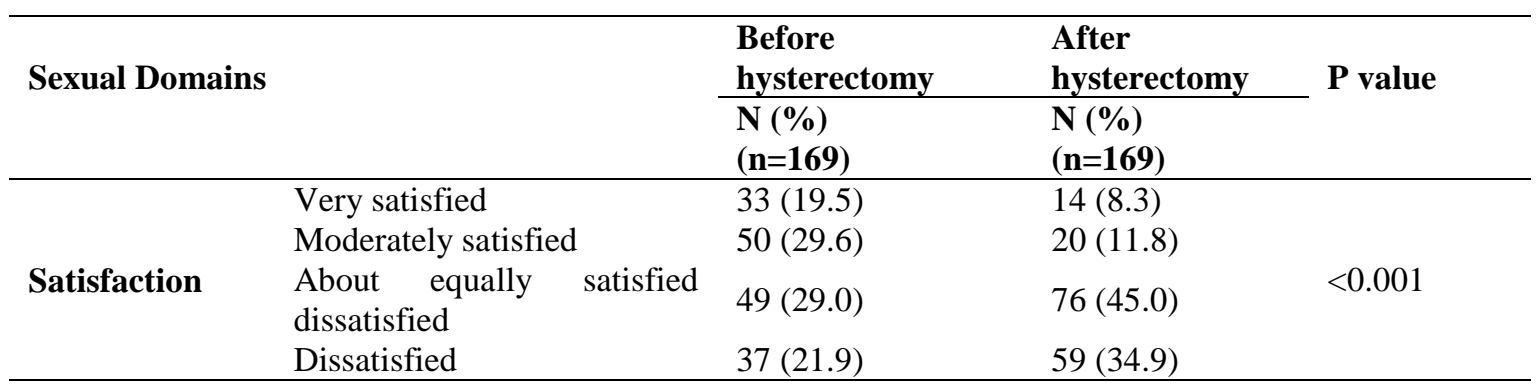

$$
\mathrm{N}=\text { Number } \quad \mathrm{P}=\text { Probability } \quad \mathrm{HS}=\text { high significant }
$$

\section{Discussion}

Those uterus need been viewed as Similarly as an organ changing and regulating vital physiological functions, (e. G. ) pregnancy Also childbirth, An sexual organ, An wellspring about energy, What's more a organ looking after those allure Also excellence of ladies. Moreover, it comprises A critical a piece about women's self-image, and misfortune from claiming uterus methods the passing of feeling from claiming womanliness [10].

The point from claiming this investigation might have been should evaluate the sway about hysterectomy on the sexuality of the tolerant and her spouse.

In the present investigation there might have
Table (3) There was a high significant reduction in the overall sexual satisfaction after hysterectomy $(\mathrm{p}<0.001)$. 
introductory phases of the cervical tumor uncovered brokenness about at sexual viewpoints.

A standout amongst the sexual issues then afterward hysterectomy might have been insufficient vaginal oil that might have been a steady Conclusion which inevitably diminished sexual fulfillment [3], [4].

Previously, [11] study, the patients who required undergone radical hysterectomy to medication of the introductory phases of cervical growth accounted for An negatively critical impact of the surgery ahead their sexual functioning, for example, lesquerella lubrication, slenderness Furthermore shortening of the vagina, Furthermore paralyzed territories around the labia, Throughout 24 months about catch up.

As stated by those current results, those level of sexual fulfillment diminished altogether following hysterectomy. This will be in understanding for [13] who accounted for that sexual fulfillment essentially diminished following hysterectomy and the diminish might have been autonomous from the kind about surgery What's more oophorectomy.

However, ladies who required undergone hysterectomy for their considerate gynecological states Previously, two other investigations encountered secondary degrees of sexual fulfillment Emulating those operation [8].

[9] led a thorough cochrane Audit comparing those sway from claiming subtotal and all out hysterectomy for considerate signs on the patients qualities, and sexuality. Six randomized regulated trials (performed the middle of 2002 Also 2010) examined those results identified with sexual function, with An catch up occasion when to up to 2 A long time. The writers discovered no proof to distinction in sexual satisfaction, or patient-reported dyspareunia the middle of subtotal and all out hysterectomy On their meta-analysis.

\section{Conclusion}

Hysterectomy impairs sexual life in the women. These women need more attention to the psychological and sexual consequence of this major surgical operation.

\section{References}

[1] D.Aschenbrenner, Avlimil taken for female sexual dysfunction. A. J. Nurs, vol.104, PP. 27 29,2014 .

[2] GA.Bachmann and NA.Phillips, Sexual dysfunction. In : Steege JF, Metzger DA, Levy BS. DA, Levy BS, eds. Chronic pelvic pain : an integrated approach. J Clin psychiatry, 62 (suppl 3): vol.33, PP.22 - 34,2016.
[3] MH.Badakhsh, F.Taftachi, F.Mehrabi and A.Derakhshan, The Effect of Hysterectomy in Securing Sexual Desire and Satisfaction. Iranian Journal of Surgery, Vol.17 (1), PP.75 - 80,2009

[4] GO.Bayram and NK.Beji , Psychosexual adaptation and quality of life after hysterectomy. Sexuality and Disability, Vol.28(1), PP.3 - 13,2010.

[5] GO.Bayram and NH.Şahin. Hysterectomy's psychosexual effects in Turkish women. Sexuality and Disability, Vol.26 (3), PP.149 - 158,2008.

[6] LA.Boardman and CK.Stockdale , Sexual pain. Clin Obss Gyn,vol.52, PP.682 - 90,2009

[7] Brucker SY, Taran FA, Bogdanyova S. (2014): Patient-reported quality-of-life and sexualfunction outcomes after laparoscopic supracervical hysterectomy (LSH) versus total laparoscopic hysterectomy (TLH): a prospective, questionnaire-based follow-up study in 915 patients. Arch Gynecol Obstet, Vol.29, PP.224230,2014.

[8] M.Kuppermann, LA.Learman, M.Schembri, Predictors of hysterectomy use and satisfaction. Obstet Gynecol, Vol.115(3), PP.543 $-551,2010$

[9] A.Lethaby, A.Mukhopadhyay and R. Naik , Total versus subtotal hysterectomy for benign gynaecological conditions. Cochrane Database Syst Rev.; 4: CD004993,vol.69, PP.247250,2012.

[10] M.Modarres, F.Rahimikian and A.Mehran, Impact of Pre-Hysterectomy Counseling on Depression among Patients Reffered to TUMS Hospitals. Hayat, Vol.19(2), PP.40-50,2013

[11] Q.Pieterse, C.Maas, M.Ter Kuile, M.Lowik, An observational longitudinal study to evaluate miction, defecation, and sexual function after radical hysterectomy with pelvic lymphadenectomy for early-stage cervical cancer. International Journal of Gynecological Cancer.; vol.16(3), PP.1119 - 29,2006.

[12] S.Tangjitgamol, S.Manusirivithaya, J.Hanprasertpong, P.Kasemsarn, Sexual dysfunction in Thai women with early-stage cervical cancer after radical hysterectomy. International Journal of Gynecological Cancer. ;vol.17(5) , PP.1104 $1112,2017$.

[13] N.Zafarghandi, F.Torkestani, , F.Zaeri , Evaluation of libido in post hysterectomy patients. Tehran University Medical Journal.; vol. 64 (11), PP.77 - 80,2006. 